\title{
NESTING SYSTEM OF THE SUBTERRANEAN TERMITE Anacanthotermes ochraceus (HODOTERMITIDAE : ISOPTERA)
}

(Received: 23.9.2009)

\author{
By \\ S.I. El-Sherif and N.A. Abd El-Latif* \\ Economic Entomology and Pesticides Department, Faculty of Agriculture, Cairo University, Giza, Egypt. \\ *Plant Protection Research Institute, Agricultural Research Center, Ministry of Agriculture, Dokki, \\ Giza, Egypt.
}

\begin{abstract}
The nesting system of the subterranean termite Anacanthotermes ochraceus (Hodotermitidae : Isoptera) was studied at El-Fayoum Governorate, Egypt. A characteristic feature of the presence of the termite nests is the appearance of small conical heaps of coarse soil particles scattered all over the surface of the infested area. Every heap leads to a network of storage chambers, dwelling chambers and connecting galleries (tunnels) all excavated by workers into the soil underneath. Storage chambers are nearly conical in shape with rising roofs, semi-globular bases and flat smooth internal walls. They are used for storing collected food materials and usually occur at depths of 5-30 cm below soil surface. Dwelling chambers are more or less similar in shape to storage chambers but comparatively larger in size. They are often occupied with different aggregated termite castes, sometimes at the depth of $20 \mathrm{~cm}$ below soil surface, but mostly at depths of $30-60 \mathrm{~cm}$ and occasionally at deeper depths reaching 150 $\mathrm{cm}$. Connecting galleries are cylindrical in shape, with very smooth inner walls. The nest consists of one main longitudinal tunnel with the chambers distributed along its sides, two main nearly parallel longitudinal tunnels connected with transverse tunnels with the chambers distributed along their sides, or a network of longitudinal straight to slightly curved tunnels connected with transverse tunnels joining between randomly scattered storage and dwelling chambers.
\end{abstract}

Key words: Anacanthotermes ochraceus - nesting system

\section{INTRODUCTION}

Termites are a group of social insects that belong to the order Isoptera. They are important pests in many countries especially in the arid tropics and subtropics (El-Sherif et al., 2009). Kassab et al. (1960) and Hafez (1980) reported that there are - at least - 3 species of subterranean termites in Egypt the most common of which is Anacanthotermes ochraceus (Burmeister) from the family Hodotermitidae. This particular species causes considerable damage to rural buildings constructed with mud bricks as its workers tunnel through the walls to reach the straw mixed with the sun-dried mud thus resulting in the collapse of attacked buildings. Termite workers further tunnel into the soil forming different types of complicated nesting systems. As a matter of fact, few authors described the nesting system of Anacanthotermes ochraceus (Clement, 1954; Kassab et al., 1960 and Said, 1979) and few studies gave preliminary observations on the nesting systems of other termite species belonging to the genus Anacanthotermes, e.g. A. ahngerianus (Ghilarov,
1962), A. turkestaincus (Krishna and Weesner, 1969) and A.macrocephalus (Roonwal, 1970).

This paper contributes to the knowledge on the nesting system of A. ochraceus in a badly infested area located at El-Fayoum Governorate, Egypt. It is based on the findings of a previous study conducted at the same area by Abd El-latif (2003) on the delineation of termite colonies.

\section{MATERIALS AND METHODS}

The study of the nesting system of $A$. ochraceus was carried out at El-Sidia village, Sennoures district, El-Fayoum Governorate, which is long-known to be commonly infested with this particular termite species. A square piece of land measuring 400 square meters $(20 \mathrm{x}$ $20 \mathrm{~m}$ ) was carefully cleaned up of any cellulose materials and devoted for a study on the delineation of termite colonies based on food consumption value, soil translocation value, duration of infestation and date of initial infestation, using P.V.C. traps filled up with clean corrugated cardboard rolls and buried horizontally into the soil to a depth of $30 \mathrm{~cm}$ (Abd El-latif, 
2003). The former study revealed delineation of 9 colonies one of which is small $\left(1-20 \mathrm{~m}^{2}\right.$ territorial area), four are medium $\left(>20-40 \mathrm{~m}^{2}\right)$ and four are large $\left(>40 \mathrm{~m}^{2}\right)$. After the termination of the colony-delineation study, which lasted for two complete years, the experimental area was left untouched for another two years to allow the completion of building the nesting systems. Three of the delineated colonies were randomly selected; the $1^{\text {st }}$ was small (at the southern side of the experimental area), the $2^{\text {nd }}$ was medium (at about the center of the experimental area) and the $3^{r d}$ was large (at the south-eastern side of the experimental area). For every selected colony, the soil at its center-point was carefully dug out horizontally as necessary and vertically to the depth of $150 \mathrm{~cm}$ in search of and to follow up the termite nest. Sketches of the nesting systems were hand-drawn to illustrate the existing storage chambers, dwelling chambers and connecting tunnels or foraging galleries (Fig.1).

\section{RESULTS}

Frequent field observations indicated that a characteristic feature of A. ochraceus nests is the appearance of small conical heaps of coarse soil particles scattered all over the surface of the infested area. Each heap is about $1 \mathrm{~cm}$ high with an area of 1 square $\mathrm{cm}$ (at the base), and leads to galleries (tunnels) excavated into the soil underneath by the termite workers. Fig. (1) illustrates the different patterns of nesting system for a small colony (right), a medium colony (middle) and a large colony (left).This figure refers to the absence of a standard nesting pattern and emphasizes that every colony acquires a different nesting system. However, the nest is - in general - a network or assemblage of chambers connected to each other by several more or less longitudinal galleries of various lengths excavated into the soil at different levels (depths).

\subsection{Storage chambers}

Field observations further indicated the occurrence of two distinct types of chambers; storage chambers and dwelling chambers. The storage chamber (Fig. 2A) is nearly conical in shape with a roof rising to $1-3 \mathrm{~cm}$ at the middle with a semi-globular base of $4-5 \mathrm{~cm}$ diameter. Its internal walls are flat and smooth. Storage chambers are usually separate from each other but, occasionally, 3 of these chambers may join together to form a relatively large chamber (Fig. 2B). Storage chambers are used for storing collected food materials (e.g. pieces of wood, straw, paper ...etc.) and are usually full of food stuff. As seen in Fig. (1), most of the storage chambers occur at depths of $5-30 \mathrm{~cm}$ below the soil surface.

\subsection{Dwelling chambers}

The dwelling chamber (Fig. 2C) is more or less similar in shape to the storage chamber but comparatively larger in size. Its roof is $2-3 \mathrm{~cm}$. high at the middle while its globular base measures 4-9 cm. in diameter. Dwelling chambers may take different shapes and sometimes two dwelling chambers may join together (Fig.2D). As in storage chambers, the walls of the dwelling chambers are also smooth and flat. Dwelling chambers are often occupied with different aggregated termite castes. Few dwelling chambers may be found at a depth of 20 $\mathrm{cm}$. below the soil surface but most of them occur at depths of 30-60 cm. and occasionally at deeper depths reaching $150 \mathrm{~cm}$. (Fig. 1).

\subsection{Connecting tunnels}

Connecting tunnels (or foraging galleries) are cylindrical in shape, with very smooth inner walls, mainly in the range of 5-9 $\mathrm{mm}$. in diameter and $10-40 \mathrm{~cm}$. in length.

\subsection{Nesting pattern}

The nest may consist of one main longitudinal tunnel with the chambers distributed along its sides (Fig. 1 right), or of two main nearly parallel longitudinal tunnels connected with transverse tunnels and the chambers distributed along their sides (Fig. 1 middle). A third nesting pattern may appear as a network of more than two longitudinal straight to slightly curved tunnels connected with transverse tunnels joining between randomly scattered storage and dwelling chambers (Fig. 1 left). Whatever the shape or pattern of the nest is, most of the dwelling chambers occur at a depth of $30-60 \mathrm{~cm}$ below the soil surface, but few galleries and dwelling chambers may occur at larger depths up to $150 \mathrm{~cm}$. In addition to soil, A.ochraceus may excavate nests into mud-brick walls in village houses making hollow irregular holes filled with pieces of straw and wood (Fig. 2E) or occupied with termite individuals (Fig. 2F).

\section{DISCUSSION}

Current results seem to coincide with the findings of the previous investigations. Clement (1954) mentioned that, in Algeria, A. ochraceus makes small halls of uncemented sand about $1 \mathrm{~cm}$ in height expelled from the galleries below. The nest consists of an assemblage of chambers excavated at different levels and joined by galleries of various lengths. Chambers are irregular in shape, mainly in the range of 15-20 $\mathrm{cm}$ in diameter, and more or less flat. They are most numerous and closer together about $30 \mathrm{~cm}$ 


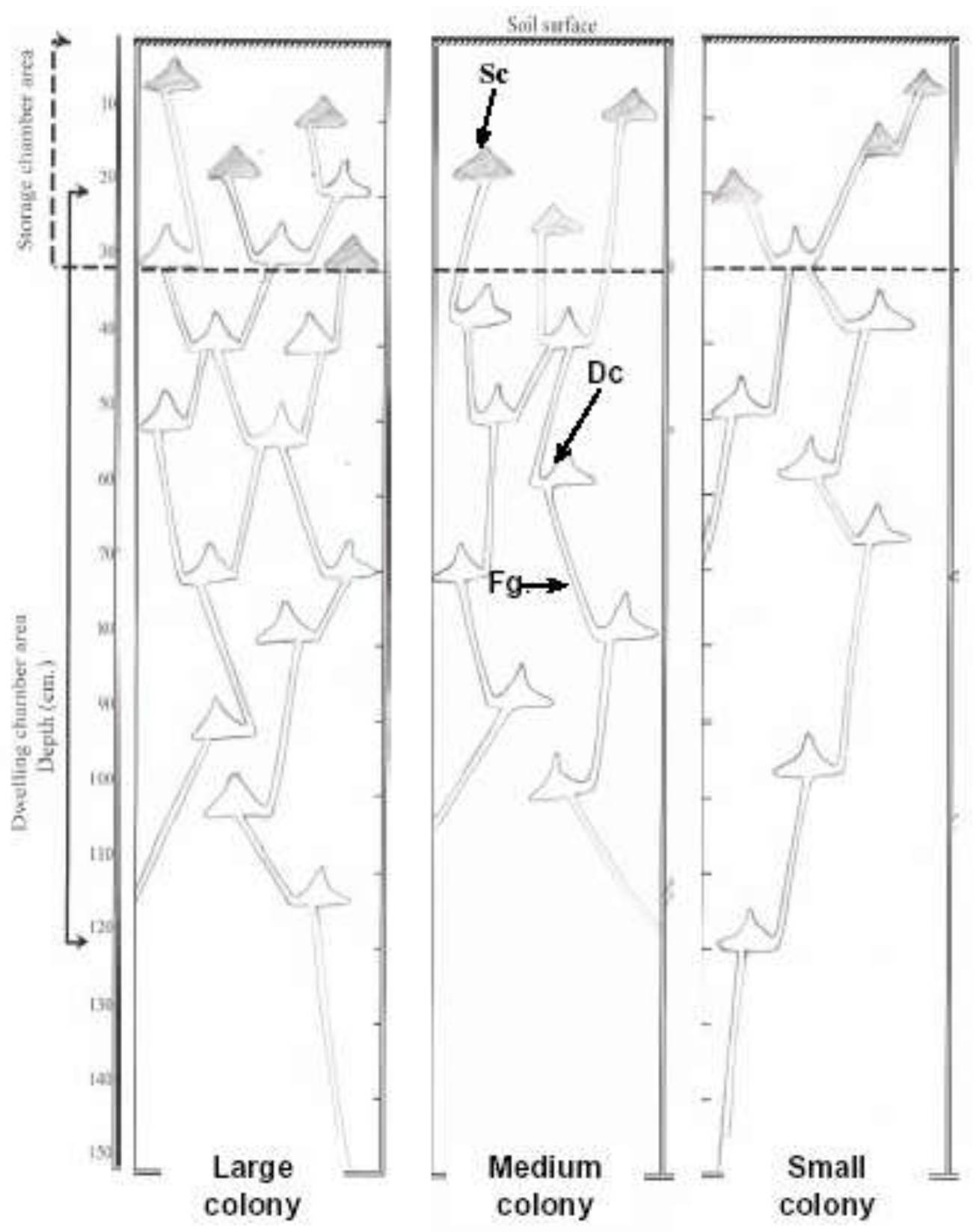

Fig. (1): Longitudinal in the soil showing the different nesting system large. medium and small colonies of $A$. ochreaceus.

Fg: Foraging galleries. Sc: Storage chamber. Dc: Dwelling chamber. Shaded areas : storage chamber.

Blank areas: Dwelling chamber. 


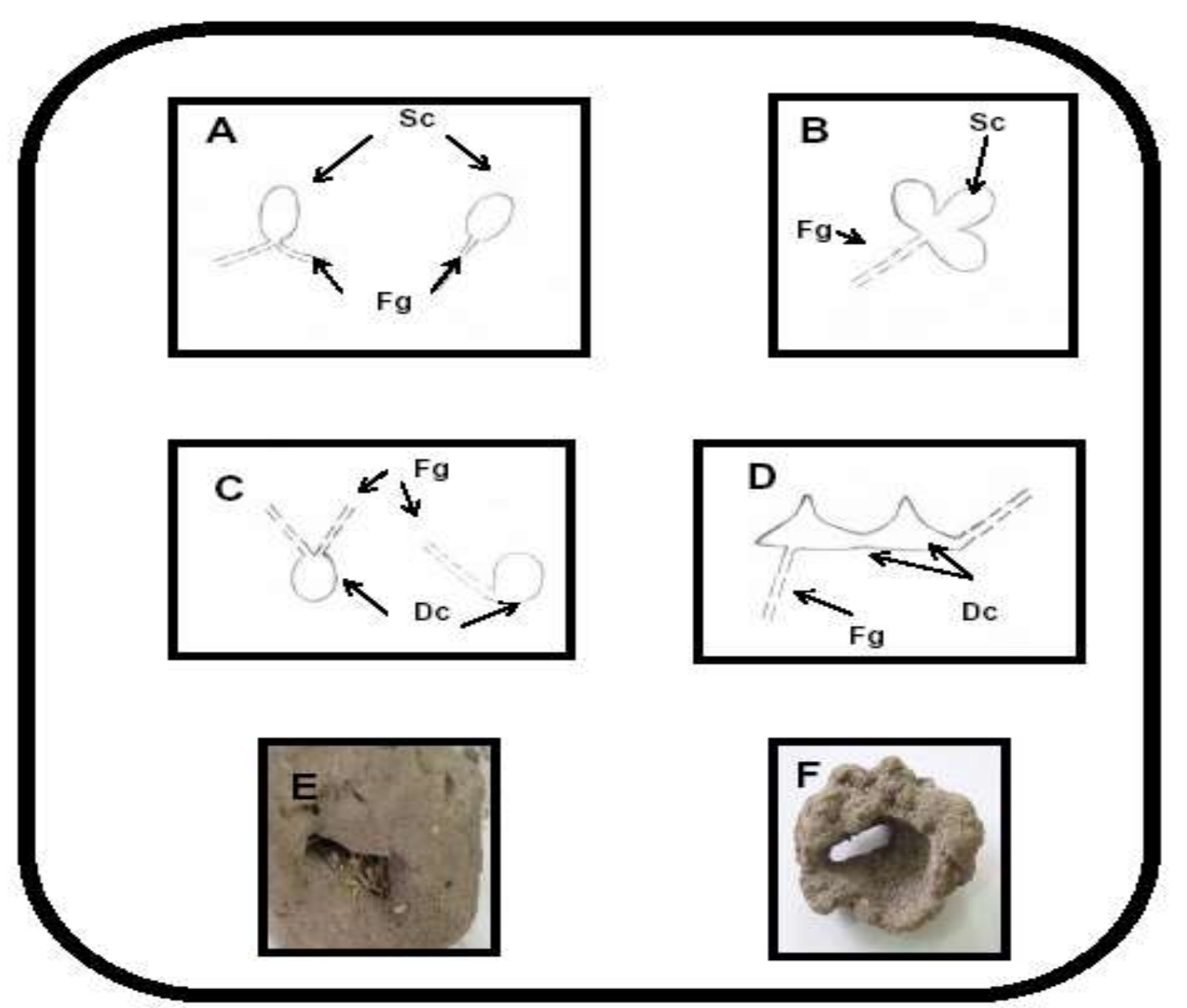

Fig. 2: Storage and dwelling chambers.

Fg: Foraging galleries, Sc: Storage chamber, Dc :Dwelling chamber.
A: Single storage chambers (longitudinal section).
B: Three joined storage chambers (longitudinal section).
C : Dwelling chambers (longitudinal section).
D: Two joined dwelling chambers (longitudinal section).
E:A storage chamber in a mud brick.
F: A dwelling chamber in a mud brick (termite individuals removed)

below the soil surface and become less numerous with longer connecting galleries down to a limit of $150 \mathrm{~cm}$. The upper chambers are used as granaries for the storage of small pieces of vegetation, and the colony occupies the chambers at intermediate depths, while the lower levels are reserved for the summer expansion of the population.

In Egypt, Kassab et al.(1960) observed that the subterranean passages of A. ochraceus ramify in all directions, and added that the location of the nest is very difficult even when extensive excavation is done. In Egypt too, Said (1979) mentioned that the subterranean nest of $A$. ochraceus is an assemblage of chambers that belong to three distinct types according to location beneath the soil surface. The upper layer (about $40 \mathrm{~cm}$. below soil surface) contains a large number of flat chambers mainly in the range of 6 $-15 \mathrm{~cm}$ in diameter each, with roofs rising to 2 $4.5 \mathrm{~cm}$ in the middle. These chambers are used for storing food. In the layer below $(40-110 \mathrm{~cm})$ the chambers become less numerous, globular in shape, and are occupied with workers, nymphs and few soldiers. From 110 to $140 \mathrm{~cm}$ below the surface, the chambers are few in number and have low flat horizontal shapes about $15-25 \mathrm{~cm}$ in diameter. These chambers form the nursery hives where numerous young nymphs and few numbers of supplementary reproductives occur. 


\section{REFERENCES}

Abd El-latif N. A. (2003). Ecological and Control Studies on Certain Subterranean Termite Species. Ph. D. Thesis, Fac. Agric., Cairo Univ., 267pp.

Clement G. (1954). Contribution a l'etude de la biologie d' Anacanthotermes ochraceus. Insectes Sociaux, 1: 194-198.

El-Sherif S. I., El-Sebay Y. M. and Abd El-latif N. A. (2009). Foraging activity of the subterranean termite, Anacanthotermes ochraceus (Burmeister) at El-Fayoum Governorate, Egypt. Fayoum J. Agric. Res. \& Dev., 23 (2): 55-64.

Ghilarov M. S. (1962). Termites of the USSR, their distribution and importance. Proc. New Delhi Symp., 1960: 131-135. UNESCO, Paris
Hafez M. (1980). Highlights of the termite problem in Egypt. Sociobiology, 5 (2): 147-154.

Kassab A., Hassan M. I., Charawi A. M. and Shahwan, A. M. (1960). The termite problem in Egypt with special reference to control. Min. Agric. Publ., Cairo, 91 PP.

Krishna K. and Weesner F. M. (1969). Biology of Termites. Vol. I Academic Press, New York, 598 PP.

Roonwal M. L. (1970). Termites of the oriental Region, p. 315-391. In "Biology of Termites" Krishna, K. and Weesner, F. (eds.), Vol. II Academic Press. New York.

Said W. A. (1979). Ecological and Toxicological Studies on Family Hodotermitidae. M. Sc. Thesis, Fac. Agric., Ain Shams Univ., 128 pp.

\author{
نظام تكوين العشوش لنوع النمل الأبيض تحت الأرضى \\ Anacanthotermes ochraceus \\ من عائلة Hodotermitidae ورتبة متساوية الأجنحة \\ سمير الثريف إبراهيم ـ ناديه عبد الثفيع عبد اللطيفع.

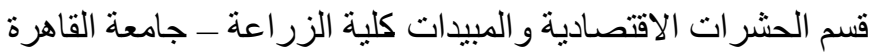

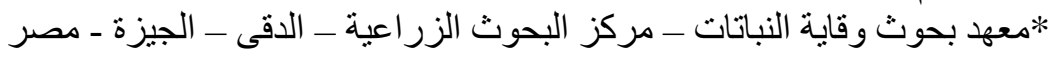

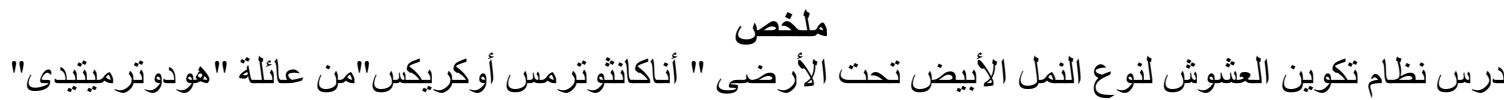

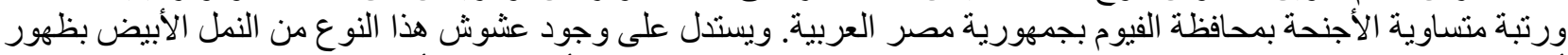

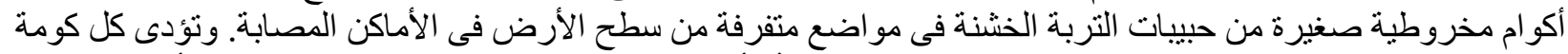

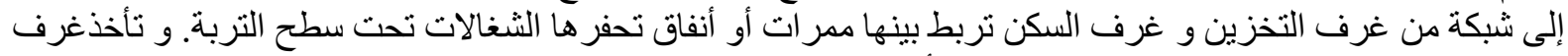

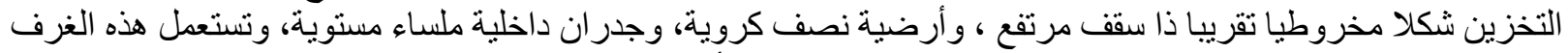

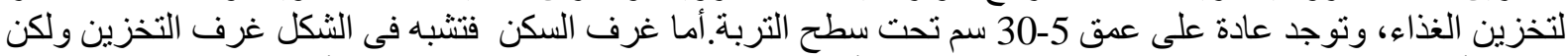

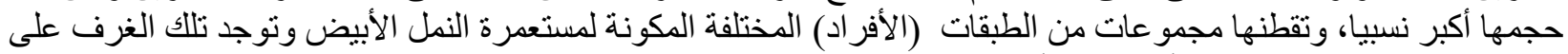

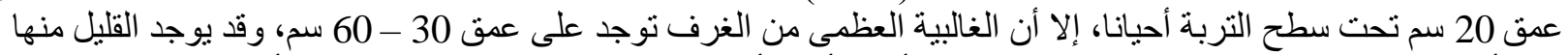

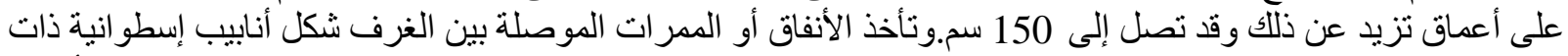

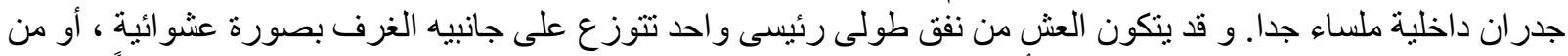

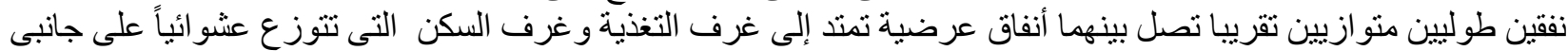

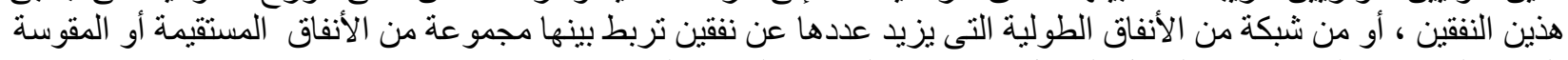

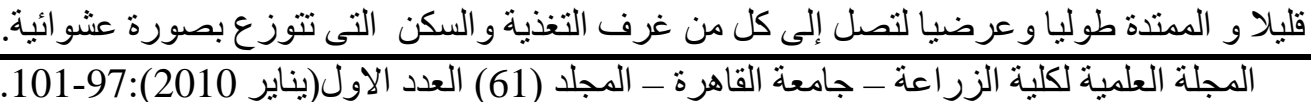

